\title{
Prediction of lower relative stability states In case of speed control of DC motor
}

\author{
Mostafa Mahmoud, Ismail \\ Department of Electrical Engineering , Al- Azhar University \\ Ahmed El - Biomey Mansour \\ Electrical Engineering, Al- Azhar University, \\ Alsayed Soliman Ahmed \\ Control \& Communications, AL- Azhar University, \\ E-Mail :mostphemto@gmail.com
}

\begin{abstract}
In industries, the control of direct current (DC) motor is a common practice thus the implementation of DC motor of speed control is important. The main purpose of motor speed control is to keep the rotation of the motor at the preset speed and to drive a system at the demanded speed. When used in speed application, speed feedback control the DC motor's speed or confirms that the motor is rotating at the desired speed. To maintain the speed, it requires the speed feedback at all times. The speed of a DC motor usually is directly proportional to the supply voltage. For instance, if we reduce supply voltage from 5 Volts to 2.5 Volts the motor will run at half or lower the speed. The advantages used DC motor is provide excellent speed control for acceleration and deceleration with effective simple torque control. This paper considers the method that are used to control speed of DC motor is phase locked loop (PLL) with proportional and data acquisition system (DAS) based to monitor the dynamic of the system and predict the change of stability for system. In this project, the method use to indicate how far the system from instability and take the reaction rapidly before system goes to unstable and to be out of control and problems occur in the rest of dependable parts on that system and useful for preventive maintenance which effective approach for reliability enhancement for the system so a failure can be detected

early or even predicted is the key point. This project presents a failure prediction method for help in preventive maintenance with rapid indication for system stability and design via bode diagram to get phase margin and gain margin by program (G-code) on LabVIEW before system operations .
\end{abstract}

\section{Introduction}

The DC motors have been popular in the industry control area for a long time, because they have many good characteristics, for example: high start torque characteristic, high response performance, easier to be linear control. The different control approach depends on the different performance of motors. Because the peripheral control devices are enough, there is the more extensive application in the industry control system. Therefore, the DC motor control is riper than other kinds of motors no matter in the theoretic study or in the research and development of the application technology, the measurement and the control system can be achieved by computer today. However, the technique of instrument design also moves forward the times of "virtual instrument", not only the designing time is shorten, but also the designing space is more elastic extension. This paper presents to guide the motor speed control field with the various advanced computer technology and the development platform of software/hardware. Let the dynamic state response of motor have a better efficiency.

This paper is to design control circuit to supervise and control the speed response of the DC motor with the virtual instrument graphic monitor software LabVIEW. To control the speed of motor and display the changes of rotational speed of motor, the better response of the system can be obtained. By the $\mathrm{NI}$ USB-6211 data acquisition (DAQ) will read the data of Hardware control circuit to transmit the signal in real time to $P C$ to be the speed response of DC motor realtime supervision. Because the DAQ card has the capability of the data storage and calculating, analysis and $A / D, D / A$ conversion ...etc., matches with the LabVIEW virtual instrument characteristic applying to detect the rotation of DC motor. This mode can substitute the traditional instruments, for instance, oscilloscope, signal generator, power supply ... etc. and the test operation is convenient. It is not easy to be influenced by the component ageing and the maintain management, and can be as the supervision basis of the machine normal operation or not.

However, National Instruments increases the productivity of engineers and scientists in developing test, control, and design systems by providing software products for a wide range of functionality. $\mathrm{NI}$ LabVIEW is the graphical development environment for creating flexible and scalable test, measurement, and control applications rapidly and at minimal cost. Using LabVIEW, the interface between engineers and scientists with real-world signals, analyze data for meaningful information, and share results and applications. The intuitive block diagrams in NI LabVIEW make it be easy to develop the custom design applications while taking advantage of the PC 
Military Technical College

Kobry Elkobbah,

Cairo, Egypt

April 3-5,2018

for processing, display, and device connectivity.

The structure of this paper is mainly divided into the

DC motor speed control system the mathematical model of DC motor and its control circuit, the software program, the computer software for relative stability results, actual measurement results and conclusions.

\section{DC motor speed control system of the} structure

\subsection{System structure}

The speed control system of the DC motor is shown in Figure 1. The main purpose is to link PC via USB transmission line and data acquisition module (NI DAQ USB-6211), then control the motor system to achieve the speed control of motor and analyze the response of the motor by software.

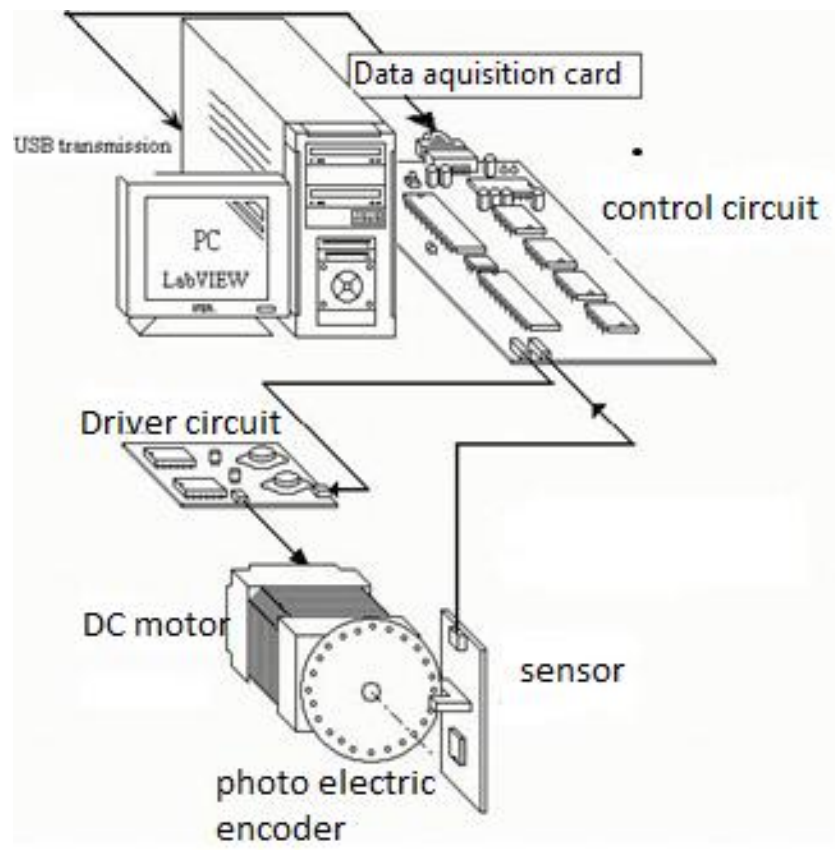

Fig. 1 The structure of speed control system

of DC motor

\subsection{System functional block diagram system}

Speed usptogucture/IEW (G-code)on pc to display the output feedback

with input reference signal in the control circuit with the This system is to recieve a pulse signal from the photo

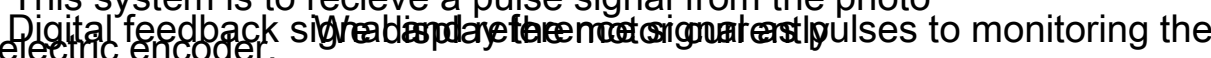
phase difference between them. 9th International Conference

on Mathematics and

Engineering Physics (ICMEP-9)

as shown in Figure 2.

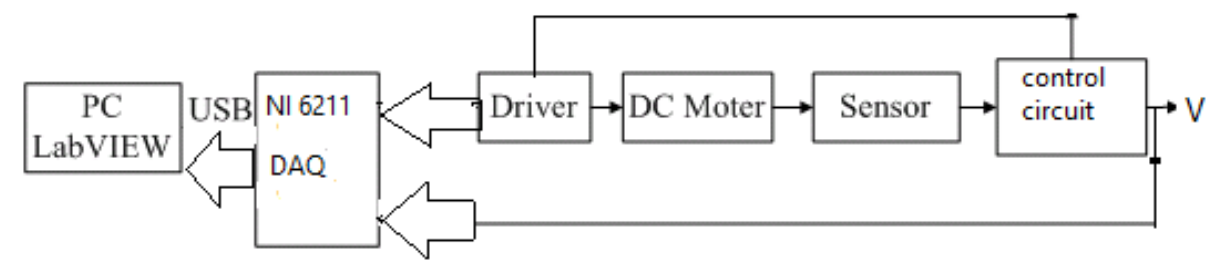

Fig. 2 speed control system of DC motor functional block diagram.

3. DC motor mathematical model and the control circuit

\subsection{DC motor mathematical model}

This DC motor system is a permanent magnet DC Motor, which is often used to the velocity tuning and the position adjustment. This paper focuses on the study of DC motor linear speed control, therefore, the permanent magnet DC motor is adopted. Make use of the armature voltage control method to control the DC motor velocity, the armature voltage controls the distinguishing feature of method as the flux fixed The control equivalent circuit of the DC motor by the armature voltage control method is shown in Figure 3.

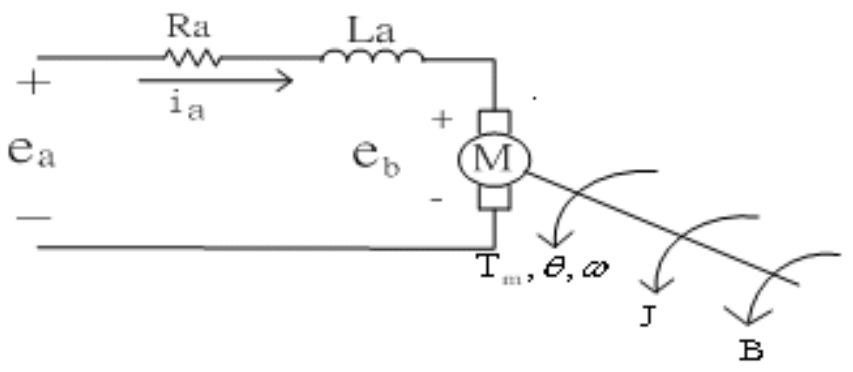

Fig. 3 The control equivalent circuit of the DC motor using the armature voltage control method

where

Ra: the armature resistance

La : the armature inductance

ia : the armature current 
Military Technical College

Kobry Elkobbah,

Cairo, Egypt

April 3-5,2018

ea: the input voltage

eb : the back electromotive force (EMF)

$\mathrm{Tm}$ : the motor torque

$\omega$ : an angular velocity of rotor

$\mathrm{J}$ : rotating inertial measurement of motor bearing

B : a damping coefficient

Because the back EMF $e_{b}$ is proportional to speed $\boldsymbol{\omega}$ directly, then after the Laplace transform,

the equations $\mathrm{ea}$ can be formulated as follows :-

$E a(s)=\left(R_{a}+S L_{a}\right) l a(s)+E_{b}(s)$

$\mathrm{Eb}(\mathrm{s})=\mathrm{K}_{\mathrm{b}} \Omega(\mathrm{s})$

$\left.\operatorname{Tm}(\mathrm{s})=\mathrm{B} \Omega(\mathrm{s})+\mathrm{Js} \Omega(\mathrm{s})=\mathrm{KT} \mathrm{Ia}_{\mathrm{a}} \mathrm{s}\right)$

To describes the DC motor armature control system

function block diagram from equations (1) to (3).

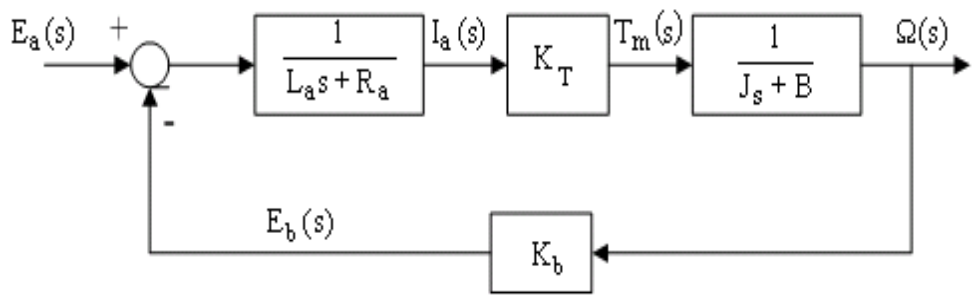

Fig.4 DC motor armature voltage control

system function block diagram

The transfer function of DC motor speed with respect to the input voltage can be written as follows,

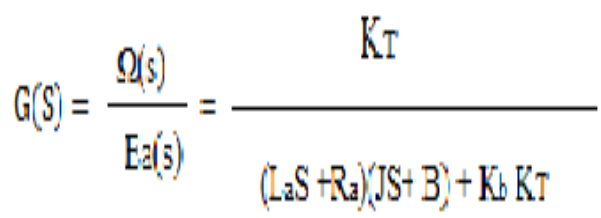

9th International Conference

on Mathematics and

Engineering Physics (ICMEP-9)

From equation (4) the armature inductance is very small in practices, hence, the transfer function of DC motor speed to the input voltage can be simplified as follow,

$$
\frac{\Omega(\mathrm{s})}{\mathrm{E}_{\mathrm{a}}(\mathrm{s})}=\frac{\mathrm{Km}}{\boldsymbol{\tau} \mathrm{S}+\mathbf{1}}
$$

Where $K_{m}=\frac{K_{T}}{R_{a} B+K_{b} K_{T}}$ is a motor gain

$$
\tau=\frac{\mathrm{Ra} J}{\mathrm{Ra}_{\mathrm{a}} \mathrm{B}+\mathrm{K}_{\mathrm{b}} \mathrm{K}_{\mathrm{T}}} \text { is the motor time constant }
$$

From equation (5), the transfer function can be drawn the DC motor system block diagram which is shown in Figure 5.

DC Motor

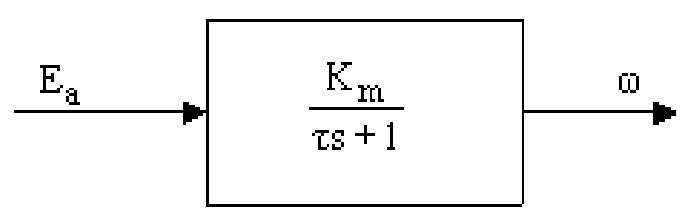

\section{Fig. 5 Simplified block diagram of DC motor armature voltage control system}

\subsection{Phase-locked loop technique in DC motor}

speed control

Phase-locked loop have been intensively used in communication and control system where accurate frequency synchronization is required. In its basic form a phase-locked loop (PLL) consists of a phase detector, a low-pass filter and a voltage-controlled oscillator(VCO) as shown in Fig.6. The VCO output signal is compared with the reference signal by the phase detector, which produces an error signal to indicate the phase difference. The phase error signal is filtered by the low-pass filter to providing a voltage proportional to the phase difference between the two signals. This voltage is used to vary the VCO frequency in such a direction that reduces the phase difference. An equilibrium state is reaches when the VCO frequency is exactly equal to the frequency of the reference-input signal. By inserting

a DC motor corresponds to VCO and eliminating the VCO from control loop. We can be synchronized to a multiple of the reference frequency as shown in Fig.7 .Such a configuration is called a frequency synthesizer (corresponds to motor speeds), which is usually used to generate frequencies in control systems.

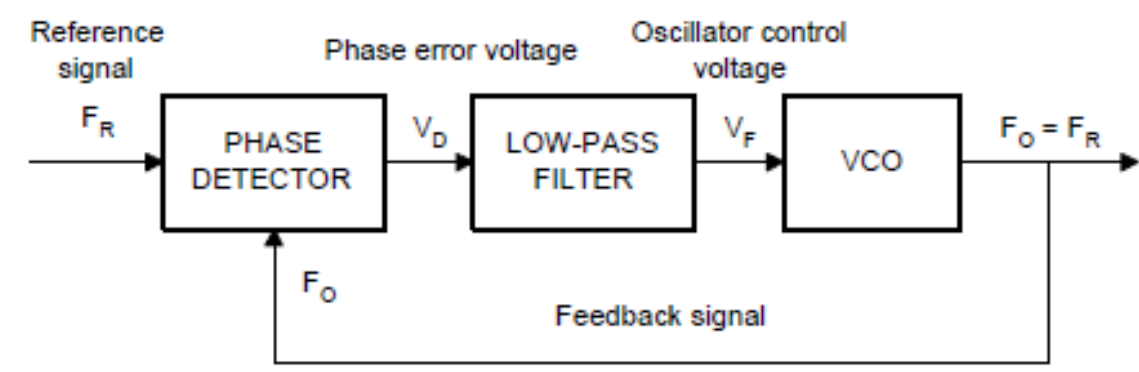

(a)

Fig. 6 Phase-locked loop block diagram for PLL basic form 


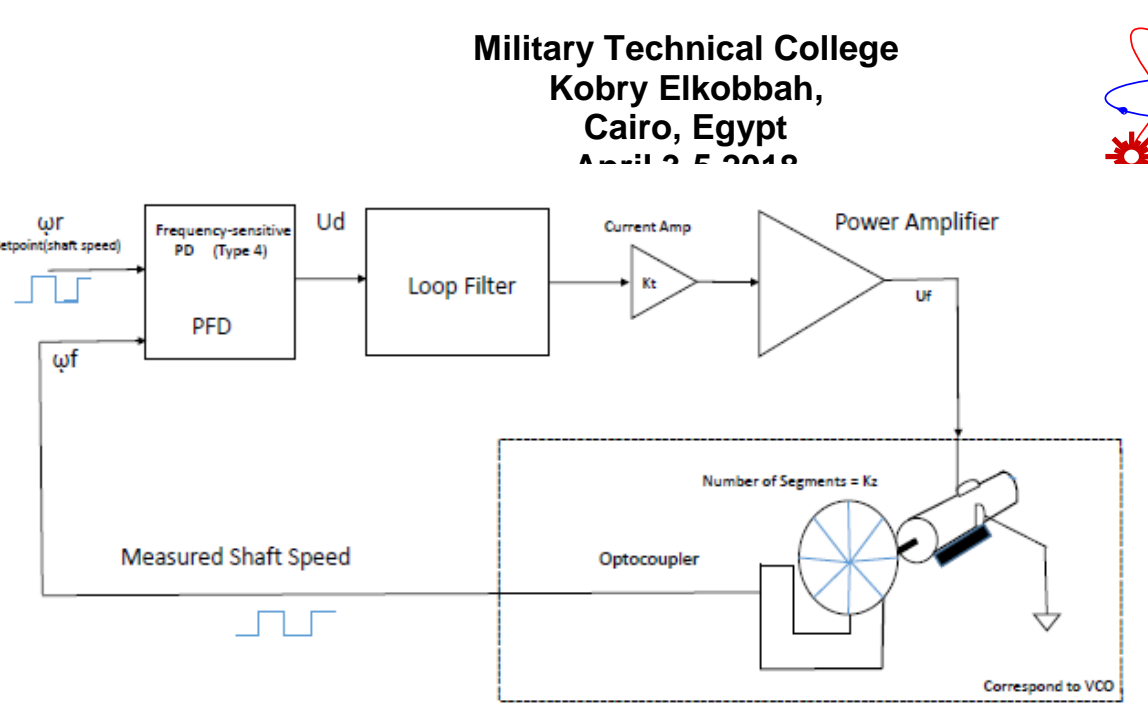

(b)

Fig.7 Block diagram of a motor-speed

control system based on PLL techniques.

The controlled plant in this paper is a DC motor. The mathematical Model of motor-speed control system

shown in Figure 8.

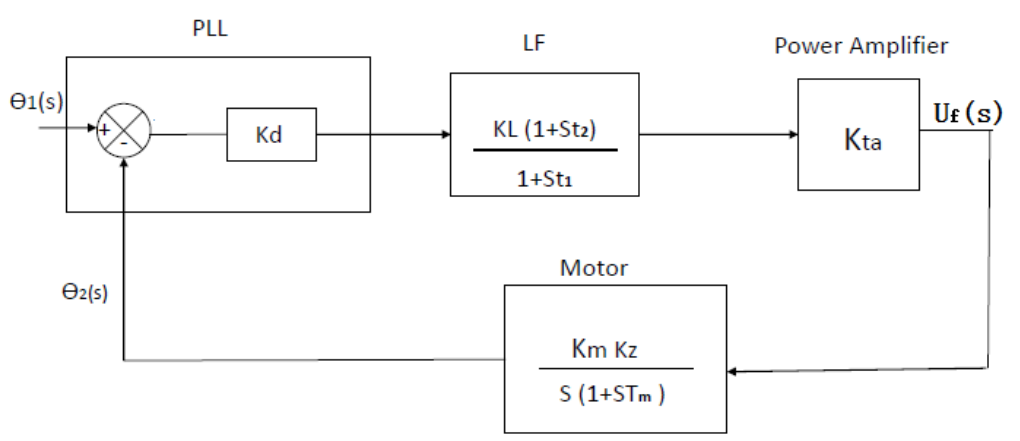

Fig.8 Linear model of proposed speed control system .

The open loop-gain transfer function of DC motor speed control system expresses as follows,

$$
\mathrm{G}(\mathrm{S}) \mathrm{H}(\mathrm{S})=\frac{\mathrm{K} \mathrm{S}\left(1+\mathrm{S} \tau_{2}\right)}{\mathrm{S}\left(1+\mathrm{S} \tau_{1}\right)\left(1+\mathrm{S} \tau_{\mathrm{m}}\right)}
$$

Whe

$$
\begin{aligned}
& \mathrm{K}=\mathrm{Kd} \cdot \mathrm{KL} \cdot \mathrm{Kta} \cdot \mathrm{Km} \cdot \mathrm{Kz} \\
& \tau_{2}=\mathrm{R}_{2} \cdot \mathrm{C} \\
& \tau_{1}=\mathrm{R} 1 . \mathrm{C}
\end{aligned}
$$

The individual blocks in Fig. 8 can be combined into fewer Blocks, a result which yields the simpler block diagram. In this system the transfer function of the forward path is defined by $G(S)$,whereas the transfer function of the feedback network (motor)is given by $\mathrm{H}(\mathrm{s})$.

\section{9th International Conference \\ on Mathematics and \\ Engineering Physics (ICMEP-9)}

When a motor-speed control system is designed practically, some

Parameters are initially given, such as the motor parameters $\mathrm{Km}$

And Tm or the number of holes $\mathrm{Kz}$ of the sector disk. The remaining

Parameters ( $\mathrm{K}$ and $\tau_{1}, \tau_{2}$ ) then have to be chosen for best dynamic performance and maximum stability of the system. There are many ways to solve this problem. It is possible to calculate the hitherto unspecified parameters by purely mathematical methods. In design engineering, however, more practical methods are preferred. In this paper we discuss familiar technique such as Bode diagram method. We applied this method by LabVIEW program design(VI) to determine relative stability states by gain and phase margin and graph them for different parameters choices and that's lead to predict the dynamic behavior of the proposed speed control system and to specify the degree of its stability.

\section{Monitor system design}

The Design of this monitor system is used of PC and DAQ card As the speed measurement with input and output pulses of the motor. Utilizing the LabVIEW software to design the monitoring system virtual instrument( $\mathrm{VI})$ programs to acquire from the $\mathrm{DC}$ motor speed control. All the monitor point status and the setting of monitor condition all can be executed and displayed on the screen menu in real time. Figure 9 shows the structure diagram of DC motor speed control monitor system. The interface between man and machine of computer based data acquisition system(DAS) for DC motor speed control system of this paper is shown in Fig 10 ,and the programs block diagrams is shown in Figure 11 and Fig 12.

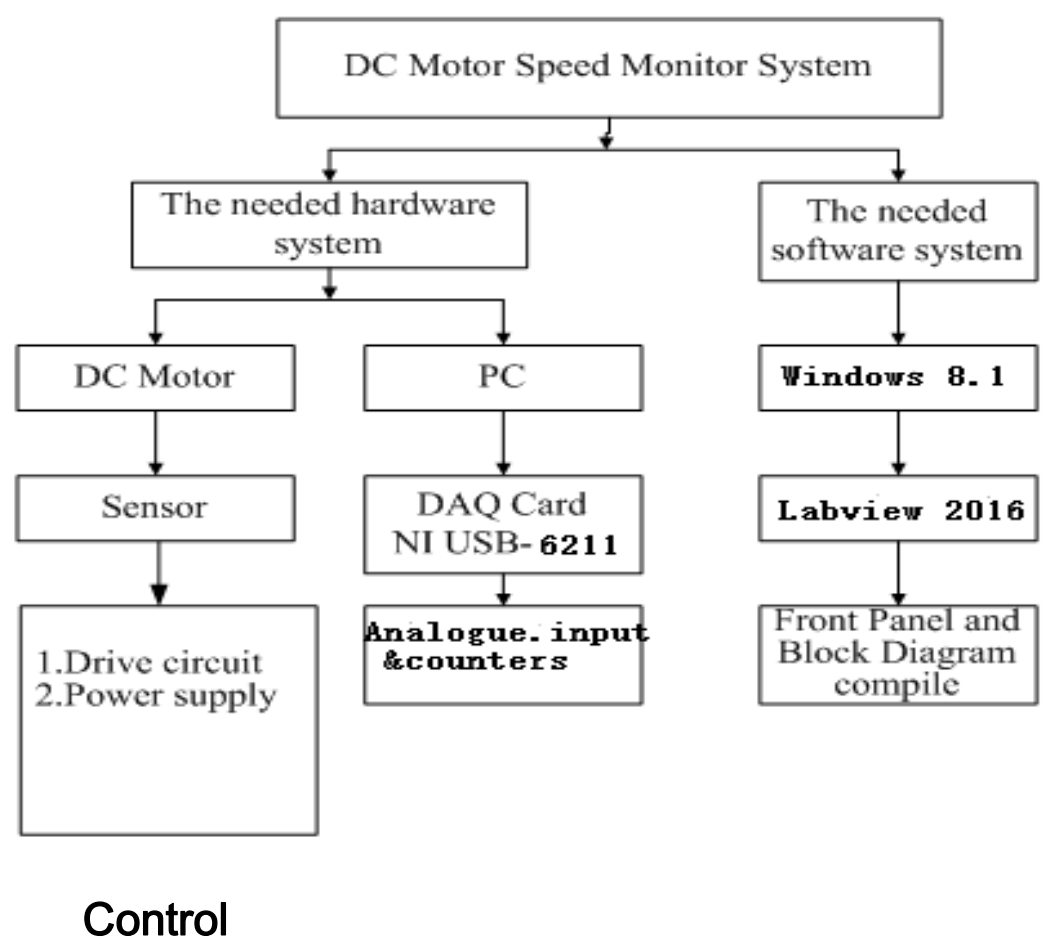


Military Technical College

Kobry Elkobbah,

Cairo, Egypt

April 3-5,2018

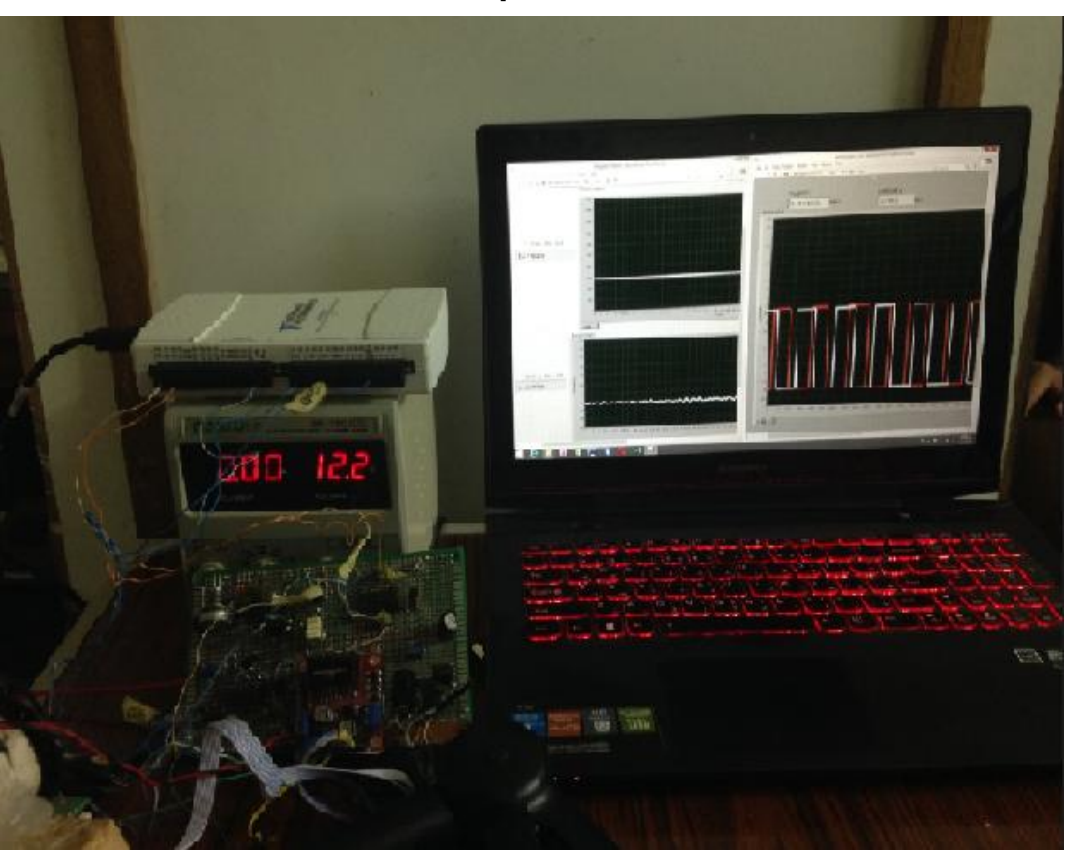

Fig. 10 Computer-based with DAS for speed monitor system

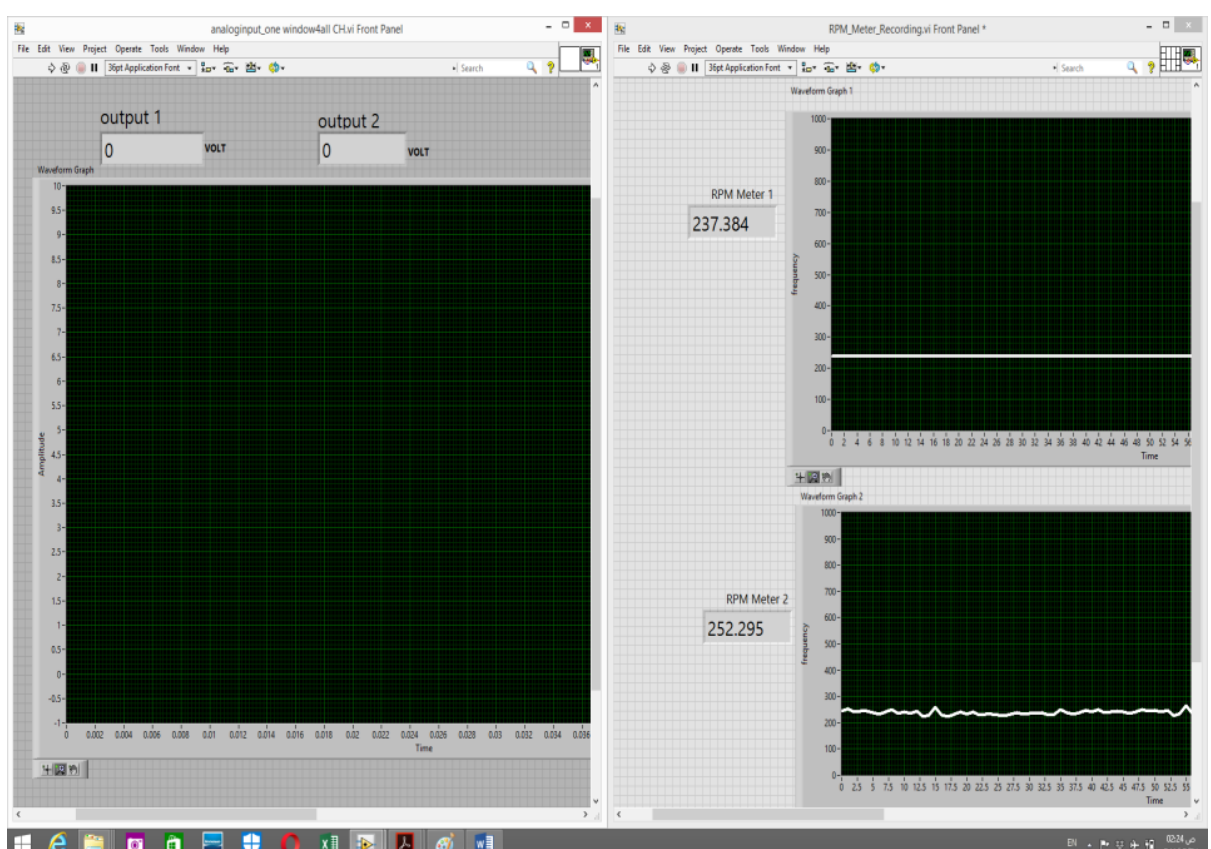

Fig. 11 Front panel of DAS for DC motor

speed control system 9th International Conference

on Mathematics and

Engineering Physics (ICMEP-9)

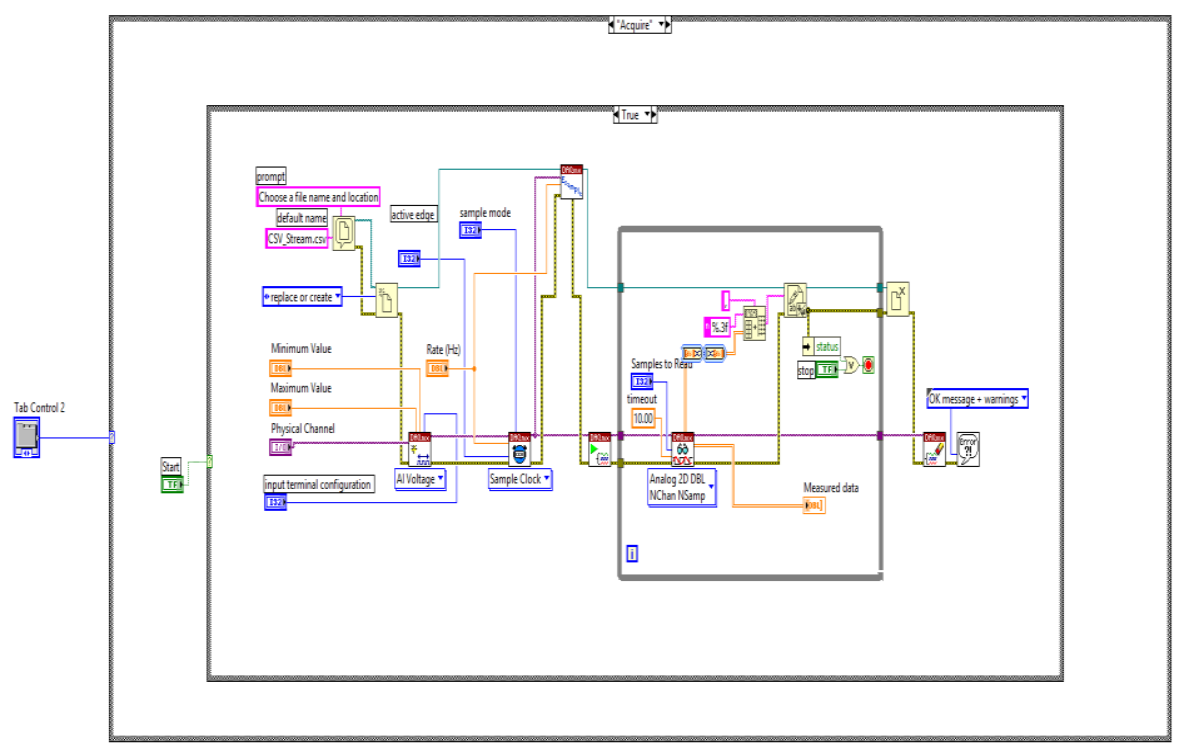

Fig. 12 Program block diagram of DAS for DC motor speed control system

\section{Experimental results}

The system is built and test using a dc motor with rated speed of $2200 \mathrm{rpm}$ and rated voltage 12 Volt and rated current of 0.8 Ampere. The rotary encoder has $20 \mathrm{ppr}$ (pulse per revolution). The range of speed control from $75 \mathrm{rpm}$ to $615 \mathrm{rpm}$.

The no-load to full-load step response of the system speed control With open and close loop are recorded and shown in Fig. 13 and 14. Figure 13 illustrates that the motor speed (open-loop system) is slow down only for about $120 \mathrm{rpm}(19 \%)$ in full-load condition.

Figure 14 illustrates that the motor speed is slow down only for about $66 \mathrm{rpm}(10 \%)$ in 1780 millisecond at loading condition, on unloading the speed motor is hunting in 1220 millisecond to 630 rpm system is oscillatory, but the average speed damps out as predicted from the model study.

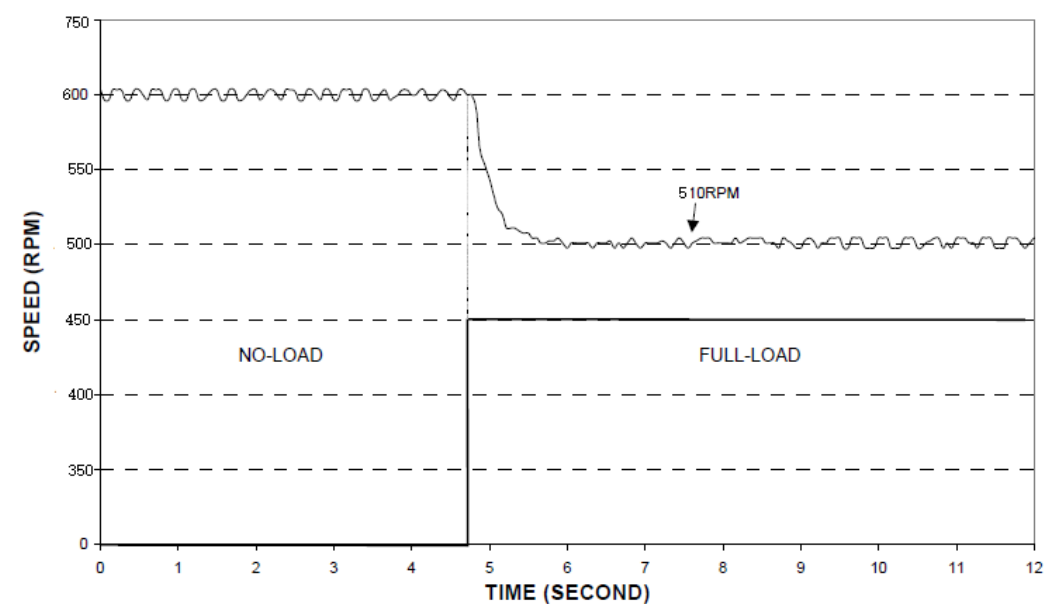

Fig.13. Step response of the open loop system with no-load and full-load conditions. 


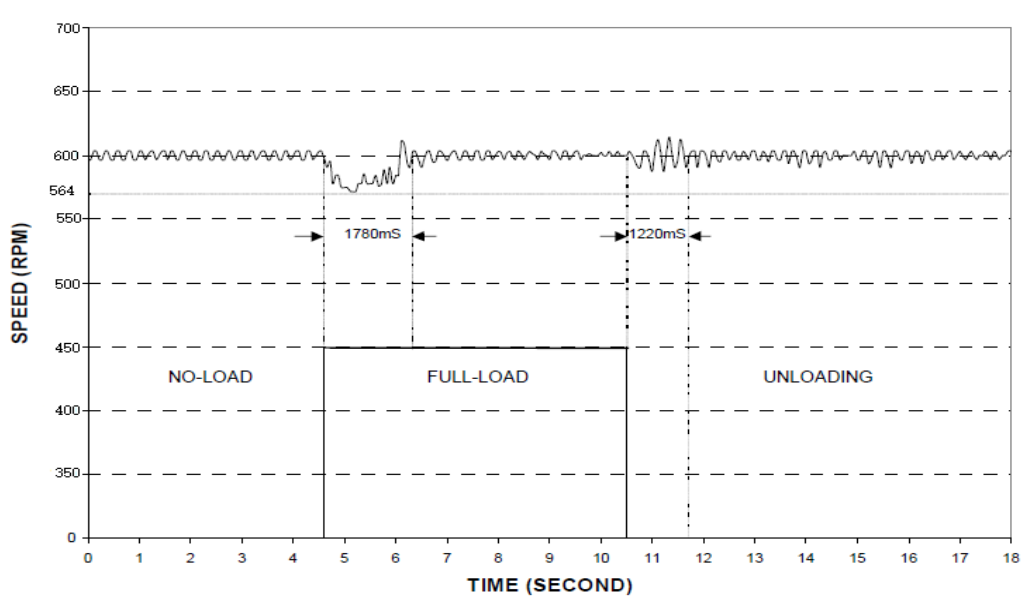

Fig.14. Step response of the close loop system with no-load and full-load conditions.

The following figures are the experimental comparison

Explanation cases at different speeds which are with respect to the control circuit to follow up or monitoring

it with four measuring points on circuit to certainly

be sure that the dynamic behavior of it is in normal case.

We take 4 channels on DAQ $\mathrm{CH} 1, \mathrm{CH} 2, \mathrm{CH} 3, \mathrm{CH} 4$

$\mathrm{CH} 1$ : Reference signal (White color)

$\mathrm{CH} 2$ : Feedback signal (red color)

CH3: comparator out from PLL (green color)

$\mathrm{CH} 4$ : PWM Signal (input signal for drive signal)(blue color)

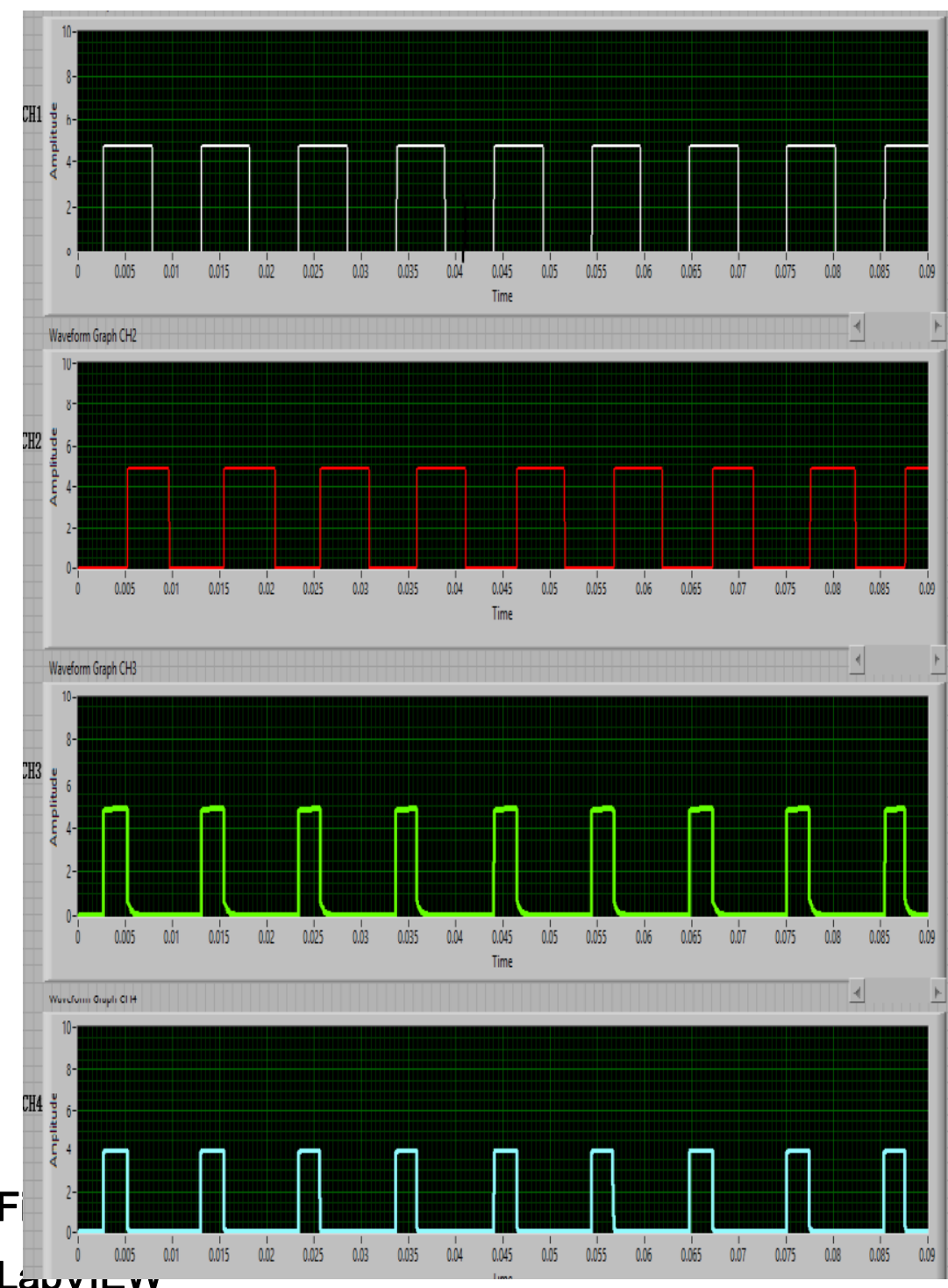

Software design program (VI) at constant speed 288 rpm for the DC motor.

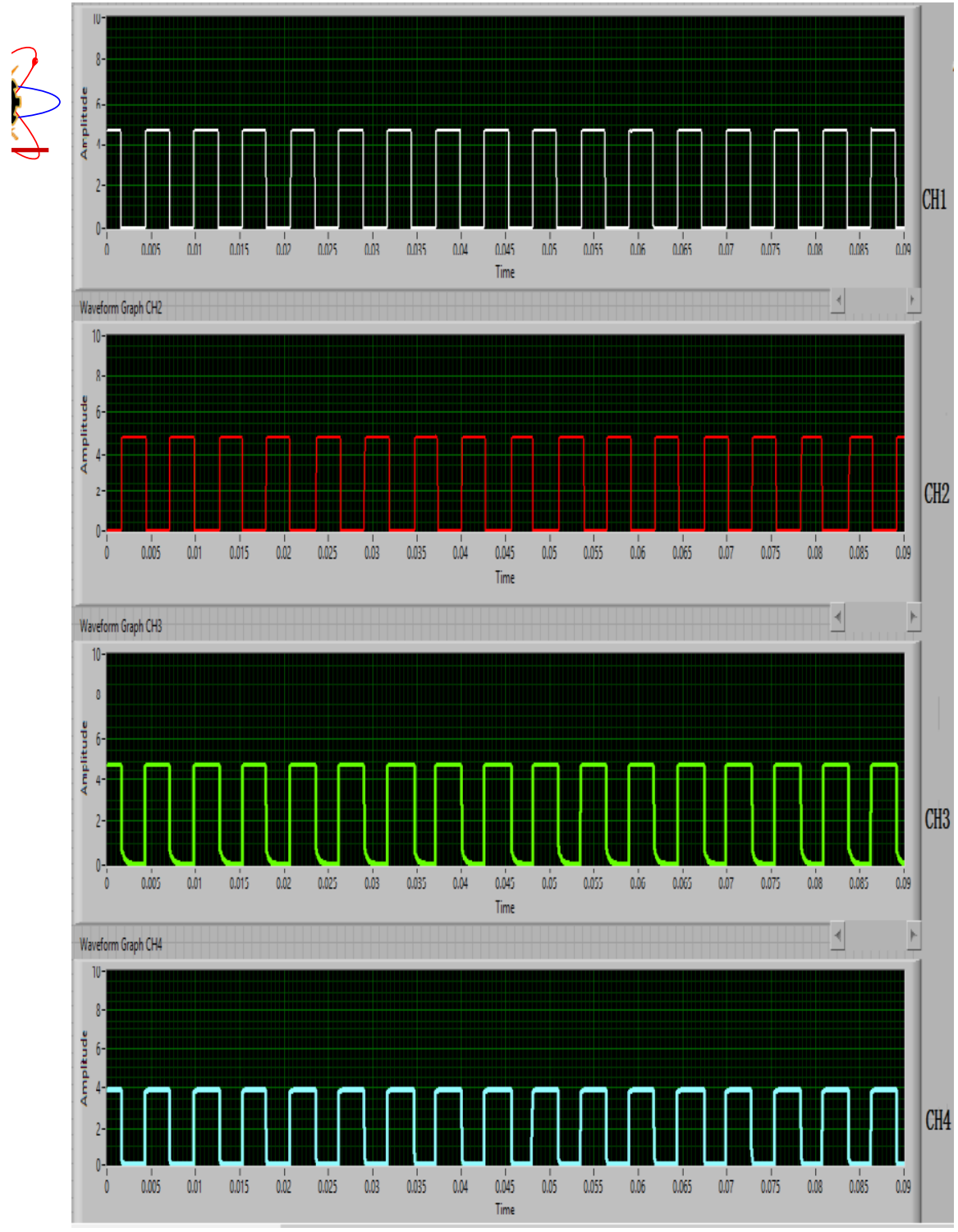

Fig. 15 (b) $\mathrm{CH} 1, \mathrm{CH} 2, \mathrm{CH} 3, \mathrm{CH} 4$ simultaneously on LabVIEW Software design program(VI) at constant speed $549 \mathrm{rpm}$ for the DC motor.

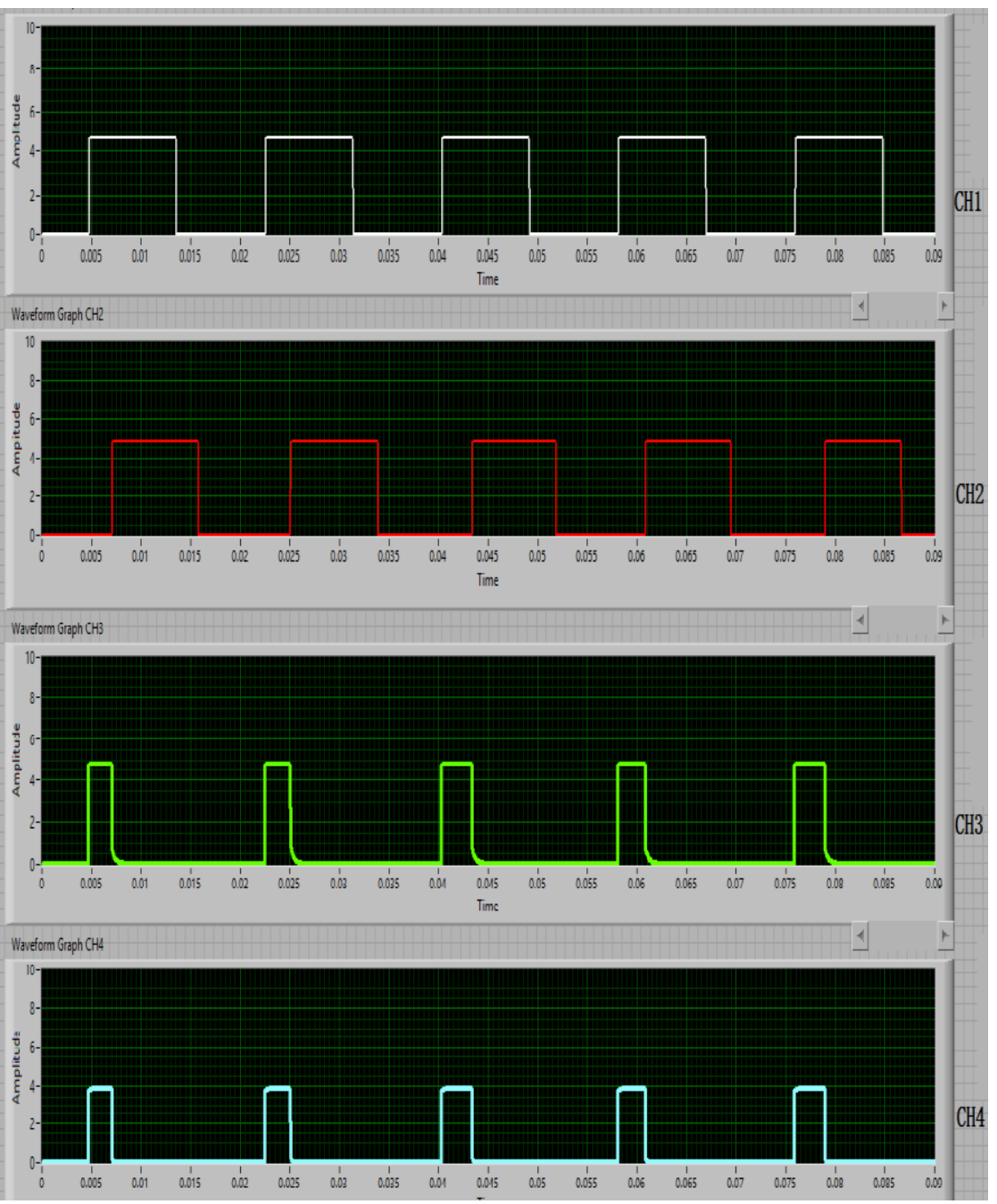

6 Fig.15 (c) $\mathrm{CH} 1, \mathrm{CH} 2, \mathrm{CH} 3, \mathrm{CH} 4$ simultaneously on LabVIEW Software design program $(\mathrm{VI})$ at constant speed $168 \mathrm{rpm}$ for the DC motor. 


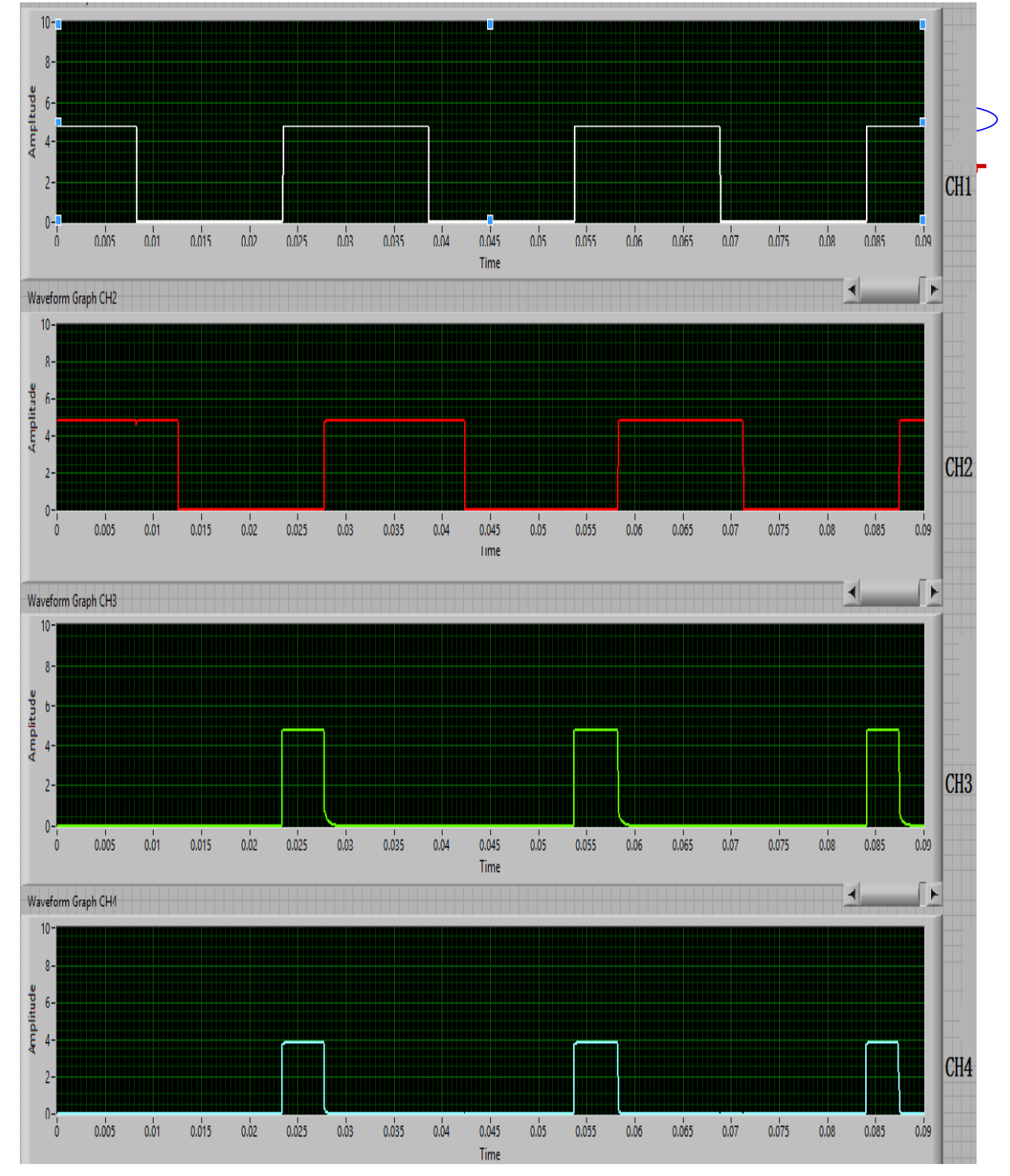

Fig.15 (d) $\mathrm{CH} 1, \mathrm{CH} 2, \mathrm{CH} 3, \mathrm{CH} 4$ simultaneously on LabVIEW software design program $(\mathrm{VI})$ at desired speed $99 \mathrm{rpm}$ for the $\mathrm{DC}$ motor.

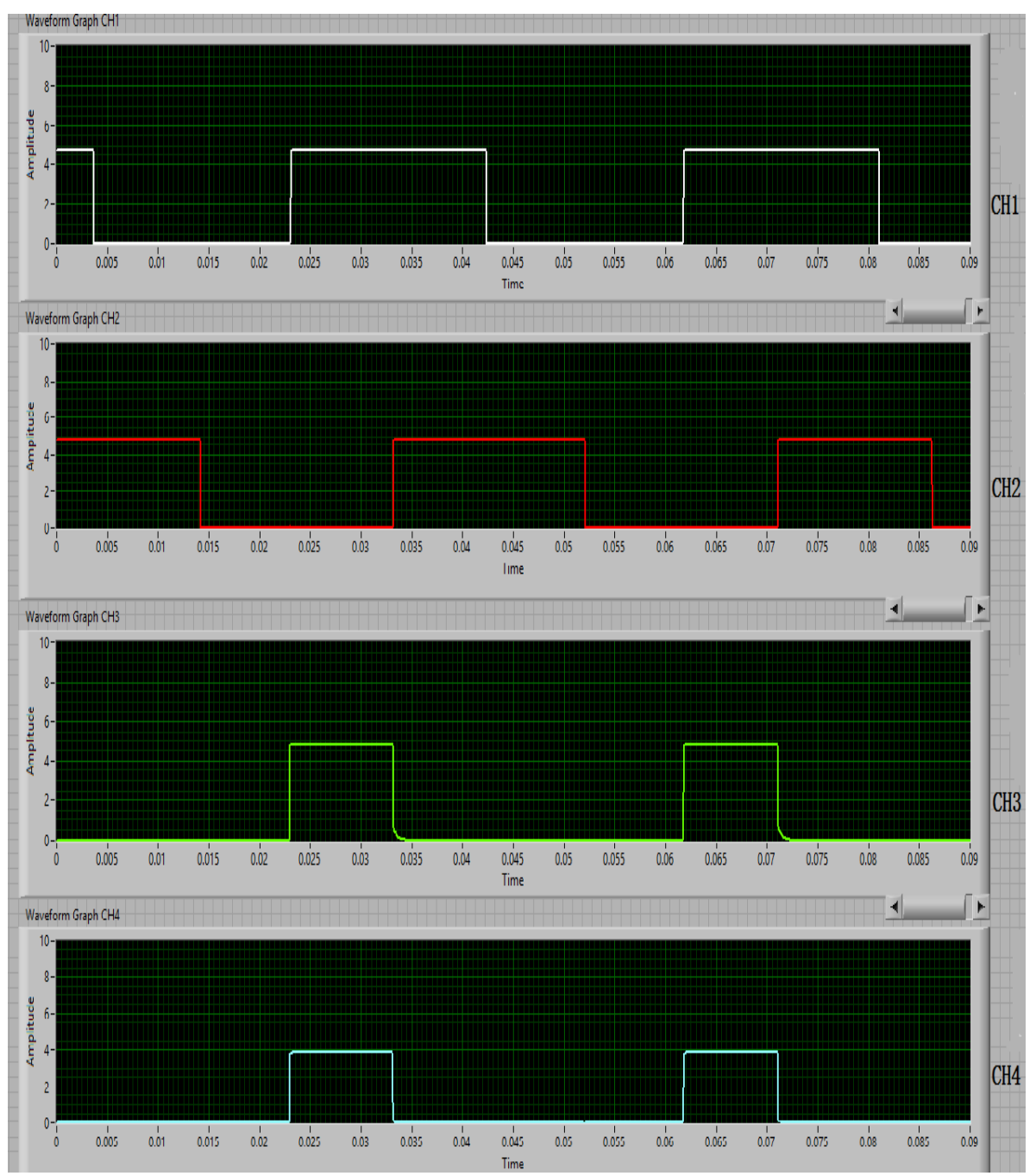

Fig. 15 (e) $\mathrm{CH} 1, \mathrm{CH} 2, \mathrm{CH} 3, \mathrm{CH} 4$ simultaneously on LabVIEW software Design program (VI)at desired speed $75 \mathrm{rpm}$ for The DC motor. 9th International Conference on Mathematics and

Engineering Physics (ICMEP-9)

To compare with figure 15 (a) to (b),(c),(d),(e) can be relatively obtain, that there is a phase difference

between $\mathrm{CH} 1$ and $\mathrm{CH} 2$ and it is clear in $\mathrm{CH} 3$, The change in PWM in $\mathrm{CH} 4$ with the speed and load variation to adapted to the desired value(reference signal)and the other important thing is to follow up the case of the system when the PLL get lock in or lock out.

\section{Conclusions}

This paper proposes to design control circuit to control the speed of DC motor using the LabVIEW software program, and display the speed of motor in real-time in order to obtain the system response and predict its stability states. Because the DAQ card has the capabilities of data scratch and transmission, matches with the LabVIEW virtual instrument characteristic and analysis. The real-time monitor of application on the motor not only can substitute the traditional instrument but also can be as the monitor basis of the machine operating normally or not. We can supervise all motors in the factory or instrument equipment indoors, and also monitor the factory operational condition from the outside. In other words, this system can monitor the motor currently, and also can join all equipment which are desired to supervise to take rapid action in early future. 


\section{References}

Military Technical College

Kobry Elkobbah,

Cairo, Egypt

April 3-5,2018

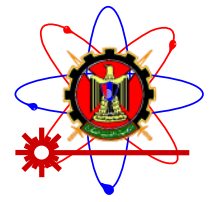

9th International Conference

on Mathematics and

Engineering Physics (ICMEP-9)

[1] DAQ USB-6211 User Manual., National Instruments, 1999

[2] LabVIEW Basics I Course Manual., National Instruments, 1999

[3] Liau, J. C., A Study of LabVIEW Aided in DC Motor

Speed Monitoring System. National Taiwan Ocean

University Department of Mechanical \& Mechatronic

Engineering 2000

[4] Srinivașan, M. B., A. Shirkhodaie, and M. Malkani,

LabVIEW program design for on-line data acquision

and predictive maintenance Proceedings of the

Thirtieth IEEE Southeastern Symposium on System

Theory, 1998 pp. 520-524

[5] Huang, J. M.., University Automatic Control,

University City Books Enterprise Inc, Kaohsiung

Taiwan, 2004

[6] Ker, D. S., Automatic Control Simulation Analysis.

Gau Lih Book co., Ltd, Taipei, Taiwan, 2004

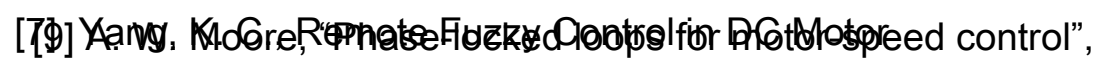

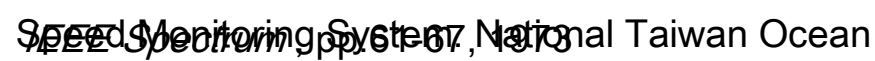

University Department of Mechanical \& Mechatronic

Engineering, 2001.

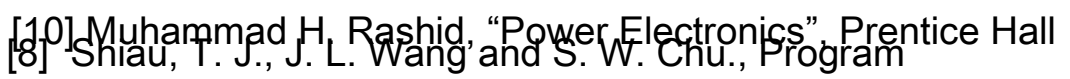

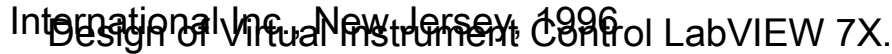

Gau Lih Book co., Ltd, 2004

[11] Guan-Chun Hsieh, "Phase-Locked Loop techniques - A

Survey", IEEE Transaction on Industrial Electronics

vol.43, no.6, pp.609-615, 1996.

[12] Garth Nash, "Phase-Locked Loop Design Fundamental",

Motorola Application Note-535, Motorola Inc., 1994

[13] A. W. Moore, "Phase-locked loops for motor-speed control"

IEEE Spectrum, pp.61-67, 1973 